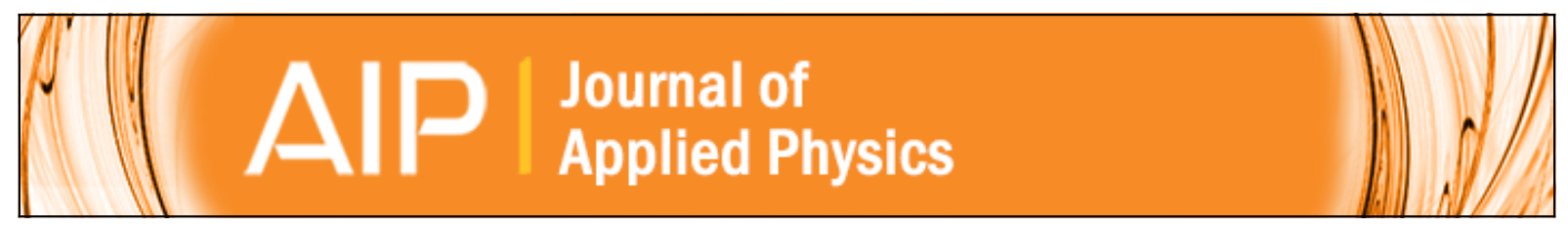

Microstructural, optical, and magnetic properties of Mn-implanted p-type GaN

Jeong Min Baik, Jong-Lam Lee, Yoon Shon, and Tae Won Kang

Citation: Journal of Applied Physics 93, 9024 (2003); doi: 10.1063/1.1572974

View online: http://dx.doi.org/10.1063/1.1572974

View Table of Contents: http://scitation.aip.org/content/aip/journal/jap/93/11?ver=pdfcov

Published by the AIP Publishing

Articles you may be interested in

Magnetic and structural properties of $\mathrm{GaN}$ thin layers implanted with $\mathrm{Mn}, \mathrm{Cr}$, or $\mathrm{V}$ ions

J. Appl. Phys. 96, 5663 (2004); 10.1063/1.1805718

Enhancement of magnetic properties by nitrogen implantation to Mn-implanted p-type GaN

Appl. Phys. Lett. 84, 1120 (2004); 10.1063/1.1647282

Magnetic properties of Mn-implanted AIGaP alloys

J. Vac. Sci. Technol. B 21, 2093 (2003); 10.1116/1.1609473

Effect of microstructural change on magnetic property of Mn-implanted p-type GaN

Appl. Phys. Lett. 82, 583 (2003); 10.1063/1.1541111

Magnetic and structural properties of Mn-implanted GaN

Appl. Phys. Lett. 78, 3475 (2001); 10.1063/1.1376659

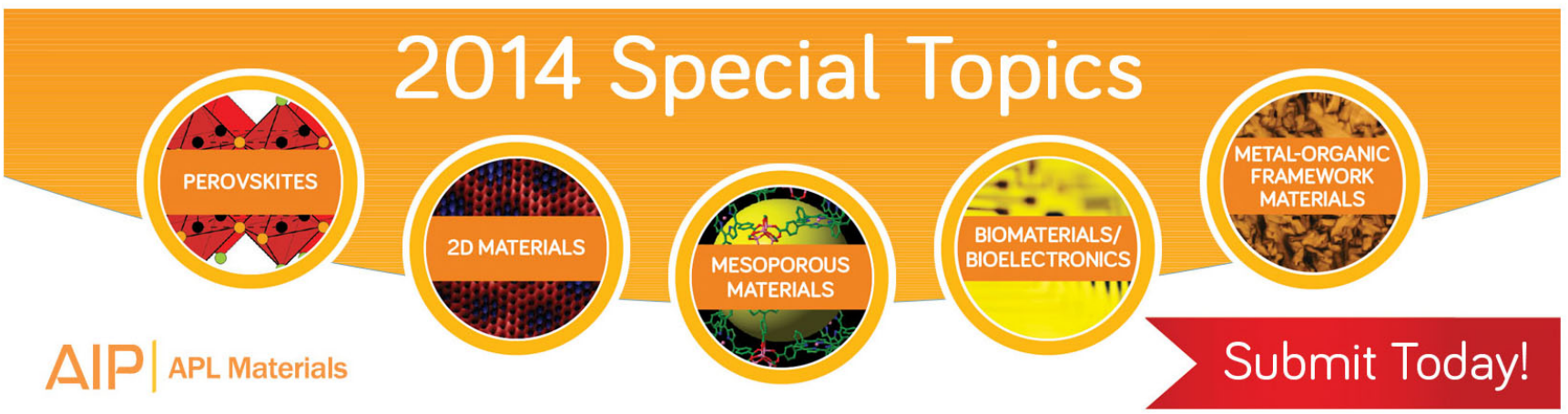




\title{
Microstructural, optical, and magnetic properties of Mn-implanted p-type GaN
}

\author{
Jeong Min Baik and Jong-Lam Lee ${ }^{a}$ \\ Department of Materials Science and Engineering, Pohang University of Science and Technology \\ (POSTECH), Pohang, Kyungbuk 790-784, Korea \\ Yoon Shon and Tae Won Kang \\ Quantum Functional Semiconductor Research Center, Dongguk University, 3-26 Pil-dong, Chung-ku, \\ Seoul 100-715, Korea
}

(Received 20 January 2003; accepted 17 March 2003)

\begin{abstract}
The effect of microstructural change on both magnetic and optical properties of Mn-implanted $p$-type $\mathrm{GaN}$ was studied. A dilute magnetic semiconductor was achieved by implanting $\mathrm{Mn}$ ions into $p$-type $\mathrm{GaN}$ and subsequently annealing. The magnetization measurement showed that the Curie temperature was the highest in the $800^{\circ} \mathrm{C}$ annealed sample due to the formation of $\mathrm{Ga}-\mathrm{Mn}$ magnetic phases. The annealing at a higher temperature of $900{ }^{\circ} \mathrm{C}$ produced antiferromagnetic $\mathrm{Mn}-\mathrm{N}$ compounds such as $\mathrm{Mn}_{6} \mathrm{~N}_{2.58}$ and $\mathrm{Mn}_{3} \mathrm{~N}_{2}$, leaving $\mathrm{N}$ vacancies. This provides evidence that $\mathrm{N}$ vacancies played a critical role in weakening the ferromagnetic property in the Mn-implanted $\mathrm{GaN}$. The photoluminescence peak at $2.92 \mathrm{eV}$ became strong after annealing at $800{ }^{\circ} \mathrm{C}$, indicating an increase in hole concentration due to an enhanced activation of Mn impurities in $p$-type GaN. The intensity of Raman modes at 290 and $670 \mathrm{~cm}^{-1}$ decreased drastically as annealing temperature increased $\left(>800{ }^{\circ} \mathrm{C}\right)$, due to the reduction in Mn-implantation-induced lattice imperfections. From this, it is proposed that the increase in magnetic properties of Mn-implanted $\mathrm{GaN}$ originated from the enhancement in the crystallinity as well as the production of $\mathrm{Ga}-\mathrm{Mn}$ magnetic phases. (C) 2003 American Institute of Physics. [DOI: 10.1063/1.1572974]
\end{abstract}

\section{INTRODUCTION}

Dilute magnetic semiconductors (DMSs) based on III-V semiconductors have attracted a great deal of attention because of their application to magnetic semiconductor devices such as spin-field effect transistors and spin-light emitting diodes. ${ }^{1-3}$ For achieving high-quality performance of these devices, semiconductors with the Curie temperature $T_{C}$ above room temperature are required. However, the reported $T_{C}$ values for InMnAs, GaMnSb, and GaMnAs were lower than $110 \mathrm{~K}^{4-6}$

$(\mathrm{Ga}, \mathrm{Mn}) \mathrm{N}$ is a very promising material because its $T_{\mathrm{C}}$ is higher than room temperature according to the theoretical calculation. ${ }^{7}$ A GaN film $\left(\geqslant 10^{21} \mathrm{~cm}^{-3}\right)$ heavily doped with Mn impurities, grown on sapphire (0001) by molecular beam epitaxy, ${ }^{8}$ showed a ferromagnetic behavior. Mn-implanted and subsequently annealed $\mathrm{GaN}$ also showed the ferromagnetic property. ${ }^{9,10}$ According to the material characterization using $\mathrm{x}$-ray diffraction (XRD) and/or transmission electron microscopy, it was proposed that the solid solution of $\mathrm{Mn}$ in $\mathrm{GaN}$ and/or $\mathrm{Ga}-\mathrm{Mn}$ binary phases would play a major role in emerging the ferromagnetic property in the Mn-doped $\mathrm{GaN}$ films. In the optical characterization of $(\mathrm{Ga}, \mathrm{Mn}) \mathrm{N}$, photoluminescence (PL) peaks were observed at 2.5 and $3.0 \mathrm{eV}$ in Mn-implanted and annealed GaN. ${ }^{11}$ The Mn impurities in $\mathrm{GaN}$, acting as a deep acceptor for electrons at an energy level of $E_{v}+1.4 \mathrm{eV}$, played a role in strongly disordering the

a) Author to whom correspondence should be addressed; electronic mail: jllee@ postech.ac.kr lattice structure. ${ }^{12}$ Despite a number of works mentioned above, no experimental evidence on the effects of such secondary phases and lattice imperfections on both the ferromagnetic and optical properties in GaN-based DMS was provided because of lack of experimental resolution. The x-ray scattering and photoemission spectroscopy using synchrotron radiation could provide quantitative information about the chemical and electronic properties, which should be crucial for understanding the origin of ferromagnetic properties in GaN-based DMS. Combining the results with optical properties in the DMS films, one can understand the ferromagnetic properties with the changes in microstructural and optical properties.

In this work, we investigated microstructural, optical, and magnetic properties of Mn-implanted $p$-type $\mathrm{GaN}$ as a function of annealing temperature. Synchrotron XRD and synchrotron radiation photoemission spectroscopy (SRPES) were employed in order to study microstructural properties of Mn-implanted p-type GaN. The optical properties of samples were analyzed through photoluminescence spectroscopy and micro-Raman spectroscopy. From these results, the effect of microstructural change on both magnetic and optical properties of $\mathrm{Mn}$-implanted $p$-type $\mathrm{GaN}$ is discussed.

\section{EXPERIMENTAL PROCEDURE}

The GaN films used in this work were grown by metalorganic chemical-vapor deposition on a (0001) sapphire substrate. An undoped GaN layer with a thickness of $1 \mu \mathrm{m}$ was grown, followed by a growth of $1-\mu \mathrm{m}$-thick $p$-type GaN 


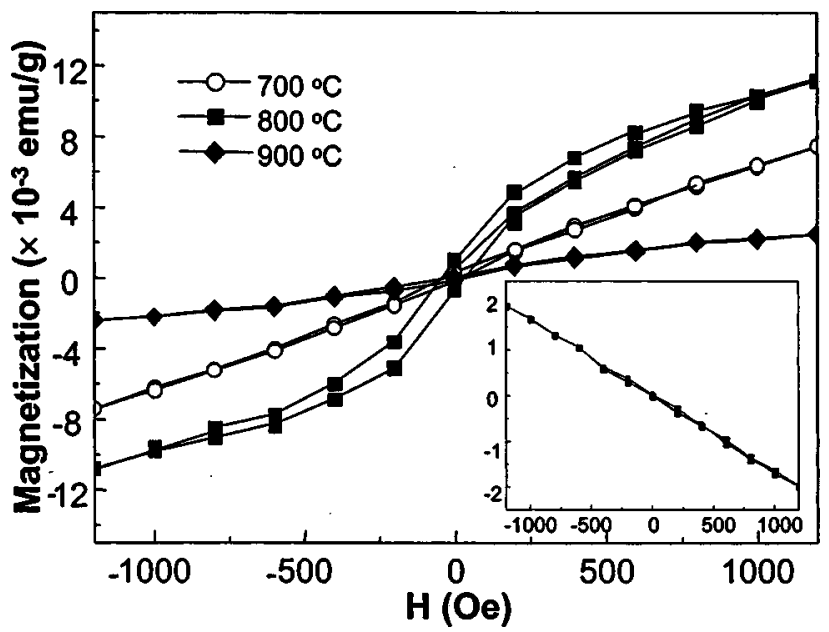

FIG. 1. Magnetization curves for Mn-implanted samples with various annealing temperatures. The inset shows the diamagnetic background of the as-grown $p$-type GaN.

doped with $\mathrm{Mg}$. Electrical activation of the grown samples was carried out at $750^{\circ} \mathrm{C}$ for 4 min by rapid thermal annealing under $\mathrm{N}_{2}$ atmosphere. Net hole concentration in the film was determined to be $2.5 \times 10^{17} \mathrm{~cm}^{-3}$ by Hall measurements. After the growth of the films, $\mathrm{Mn}^{+}$ions were implanted into the $p$-type $\mathrm{GaN}$ films with an energy of $180 \mathrm{keV}$ and the dose of $5 \times 10^{16} \mathrm{~cm}^{-2}$. All samples were held at $350{ }^{\circ} \mathrm{C}$ during the implantation to avoid amorphization. Subsequent annealing at $700-900{ }^{\circ} \mathrm{C}$ for $30 \mathrm{~s}$ was performed under flowing $\mathrm{N}_{2}$ gas in a face-to-face condition. Magnetization measurements were carried out using a superconducting quantum interference device magnetometer (MPMSXL, Quantum Design Co., Ltd).

High-resolution XRD and SRPES using synchrotron radiation were carried out at the $3 \mathrm{C} 2$ and $8 \mathrm{~A} 1$ beamlines at Pohang Accelerator Laboratory (PAL). For high-resolution XRD measurements, the wavelength of incident $\mathrm{x}$ ray was set at $1.488 \AA$ by a double bounce Si (111) monochromator. The energy resolution of binding energy in the SRPES measurements was $\pm 0.05 \mathrm{eV}$. The binding energy of core level spectra was calibrated with the peak position of the $\mathrm{Au} 4 f$ core level of an Au foil and that of the valence band spectra with the Fermi level of the Au foil. The measurements of Raman spectroscopy were performed at room temperature using an NRS-2100 spectrometer (JASCO, Japan) equipped with a triple-grating monochromator and a coherent Ar laser (Innova 90C) at $5145 \AA$. In the measurements, a microRaman option using an $\mathrm{LN}_{2}$-cooled charge coupled device was used. The scattered light was detected in backscattering geometry. PL measurements were carried out using a $0.75 \mathrm{~m}$ monochromator equipped with an ultraviolet-sensitive photomultiplier. The excitation source was the $325 \mathrm{~nm}$ line of a $\mathrm{He}-\mathrm{Cd}$ laser with the total power of $50 \mathrm{~mW}$.

\section{RESULTS}

\section{A. Magnetic properties}

Figure 1 shows magnetization curves at $10 \mathrm{~K}$ for samples annealed at $700-900{ }^{\circ} \mathrm{C}$. The magnetization curves

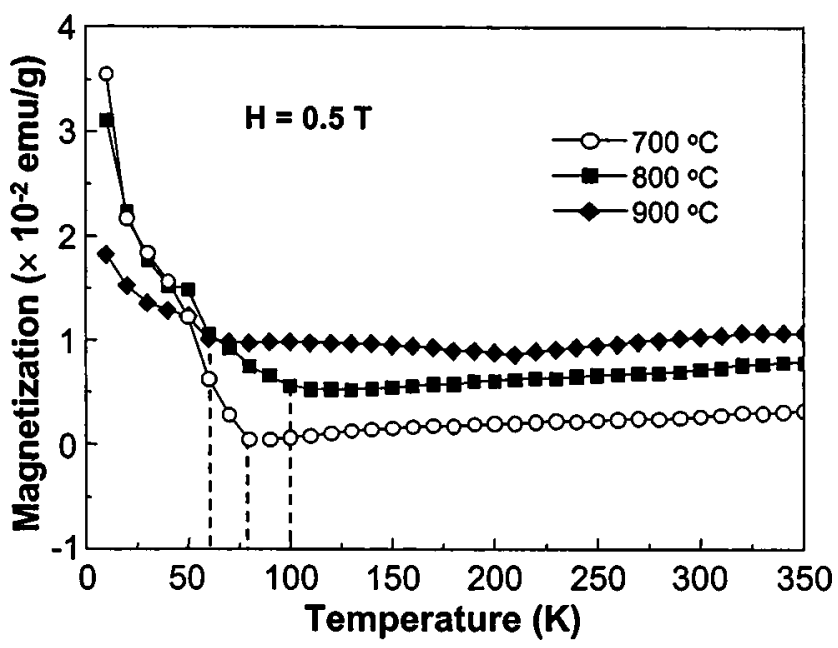

FIG. 2. Temperature dependent magnetization for Mn-implanted and annealed GaN. Samples were annealed at 700,800 , and $900{ }^{\circ} \mathrm{C}$.

were obtained with the applied field parallel to the plane of samples. The diamagnetic background of GaN layer was subtracted. The hysteresis loops showed clear ferromagnetic behavior of the samples. It was easily found that the ferromagnetic signal for the $800^{\circ} \mathrm{C}$ annealed sample was the strongest among all annealed samples. With increasing annealing temperature, the coercive field $\left(H_{C}\right)$ increased from 21 to 79 Oe. However, the residual magnetization $\left(M_{R}\right)$ was the highest in the $800^{\circ} \mathrm{C}$ annealed sample.

Temperature dependent magnetization $(M-T)$ measurements were carried out up to $350 \mathrm{~K}$ at a constant applied magnetic field of 0.5T, as shown in Fig. 2. Even though $T_{C}$ is lower than the previously reported values, ${ }^{8,10}$ the $800{ }^{\circ} \mathrm{C}$ annealed sample exhibited the highest $T_{C}(100 \mathrm{~K})$ among all annealed samples. The temperature dependency of magnetic moment showed an anomalous increase and discontinuous change below about $70 \mathrm{~K}$. This supports that Mn-related compounds or alloys were included in the present samples.

\section{B. Microstructural analysis}

Figure 3(a) shows XRD profiles of Mn-implanted GaN samples with various annealing temperatures. Compared to

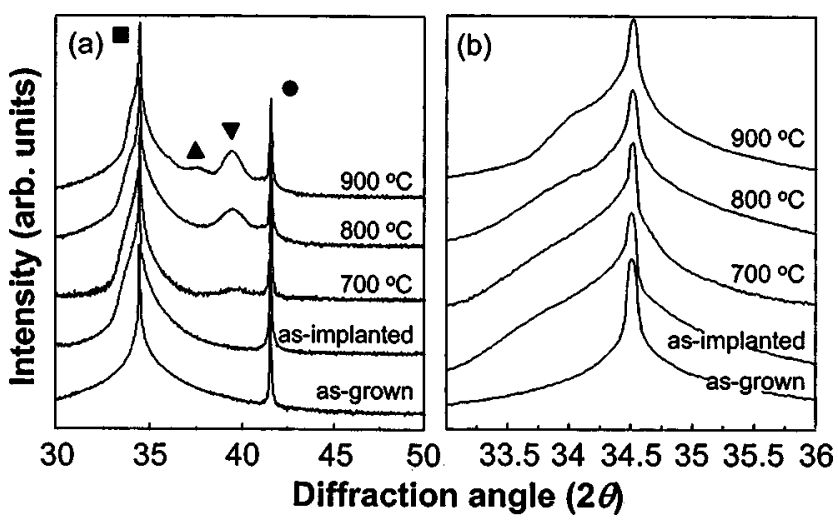

FIG. 3. (a) Change of XRD scans for the Mn-implantated GaN with the annealing temperature. (b) Expanded view at around GaN (0002) peak; (ם) $\mathrm{GaN},(\bullet) \mathrm{Al}_{2} \mathrm{O}_{3},(\boldsymbol{\nabla}) \mathrm{Mn}_{6} \mathrm{~N}_{2.58},(\mathbf{\Delta}) \mathrm{Mn}_{3} \mathrm{~N}_{2}$. 

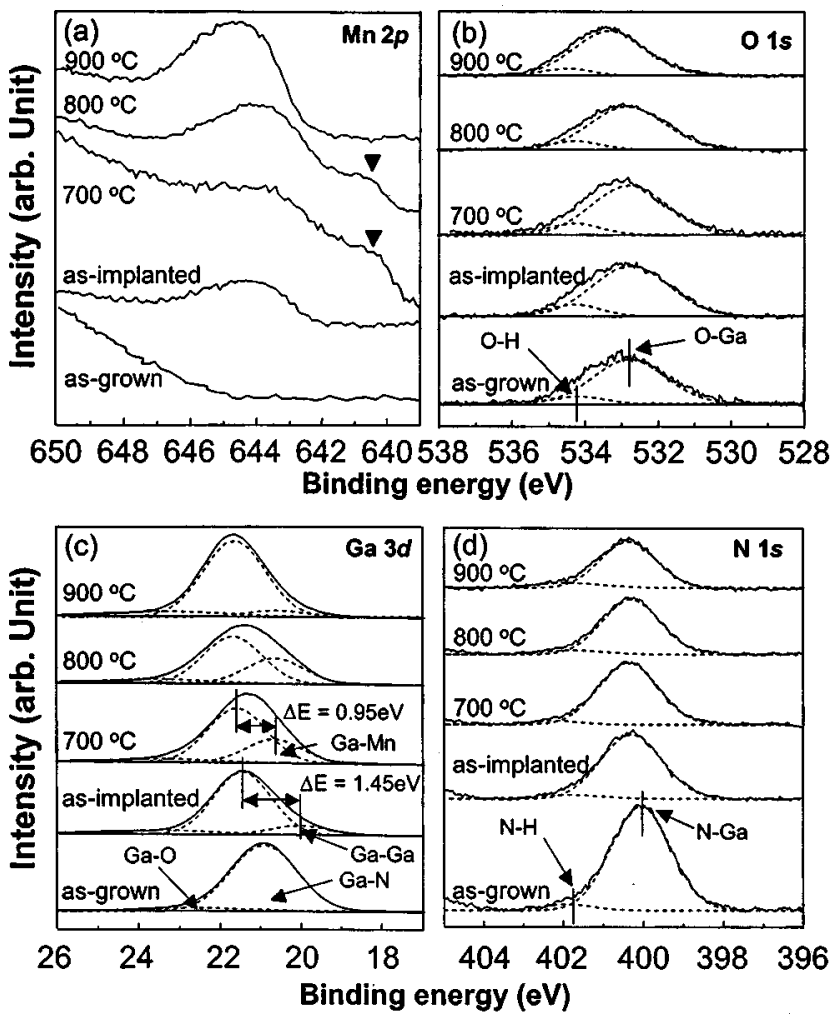

FIG. 4. Change of SRPES spectra for (a) Mn $2 p_{3 / 2}$, (b) O $1 s$, (c) Ga $3 d$, and (d) $\mathrm{N} 1 s$ core levels in Mn-implantated GaN with various annealing temperatures.

the as-grown sample, no reaction between $\mathrm{Mn}$ and $\mathrm{GaN}$ was observed in the as-implanted one. After annealing at $700{ }^{\circ} \mathrm{C}$, the $\mathrm{Mn}-\mathrm{N}$ binary phase of $\mathrm{Mn}_{6} \mathrm{~N}_{2.58}$ was produced. The $\mathrm{Mn}_{6} \mathrm{~N}_{2.58}$ peak intensity increased with the annealing temperature. When the sample was annealed at $900{ }^{\circ} \mathrm{C}$, a new peak corresponding to $\mathrm{Mn}_{3} \mathrm{~N}_{2}$ was observed. Figure 3(b) shows enlarged XRD scans ranging from $2 \theta=33^{\circ}$ to $36^{\circ}$. A shoulder was found at the lower angle side of GaN (0002) peak and its intensity became larger at higher annealing temperature. The shoulder could attribute to the strain along the GaN $c$ axis, resulting from the decrease of implantationinduced damage during the annealing. ${ }^{13}$

Figure 4 shows the change of SRPES spectra of Mn $2 p_{3 / 2}, \mathrm{O} 1 s, \mathrm{Ga} 3 d$, and N $1 s$ core levels with annealing temperature. In order to remove surface oxides, the samples were in situ etched about $50 \AA$ using Ar ion sputtering. Only one peak was observed in the $\mathrm{Mn} 2 p_{3 / 2}$ spectra for both asimplanted and $900{ }^{\circ} \mathrm{C}$ annealed samples, as shown in Fig. 4(a). The peak could be either an $\mathrm{Mn}-\mathrm{N}$ bond or a $\mathrm{Mn}-\mathrm{O}$ bond. As annealing temperature increased, the peak intensity became larger. In Fig. 4(b), it is apparently found that the intensity of $\mathrm{O} 1 s$ peak is independent of annealing temperature. This means that the main peak in Fig. 4(a) corresponds to the $\mathrm{Mn}-\mathrm{N}$ bond rather than the $\mathrm{Mn}-\mathrm{O}$ one. The presence of $\mathrm{Mn}-\mathrm{N}$ bond is in good agreement with the XRD data in Fig. 3. In the samples annealed at 700 and $800{ }^{\circ} \mathrm{C}$, a new peak was located at a binding energy of $640.5 \mathrm{eV}$, lower by $\sim 3.0 \mathrm{eV}$ than the $\mathrm{Mn}-\mathrm{N}$ binding energy. This could be either metallic $\mathrm{Mn}-\mathrm{Mn}^{14}$ or $\mathrm{Ga}-\mathrm{Mn}$ bonds. The origin of the peak was revealed by the SRPES spectra of Ga $3 d$, shown in Fig.
TABLE I. Relative concentrations (\%) of chemical bonds determined from the Ga $3 d$ SRPES spectra in Fig. 3(b). The values in parentheses represent FWHM value of each bond.

\begin{tabular}{lcccc}
\hline \hline \multicolumn{1}{c}{ Sample } & $\begin{array}{c}\mathrm{Ga}-\mathrm{N} \\
(1.52 \mathrm{eV})\end{array}$ & $\begin{array}{c}\mathrm{Ga}-\mathrm{O} \\
(2.71 \mathrm{eV})\end{array}$ & $\begin{array}{c}\mathrm{Ga}-\mathrm{Ga} \\
(1.42 \mathrm{eV})\end{array}$ & $\begin{array}{c}\mathrm{Ga}-\mathrm{Mn} \\
(1.50 \mathrm{eV})\end{array}$ \\
\hline As grown & 91.2 & 8.8 & $\ldots$ & $\ldots$ \\
As implanted & 81.9 & 10.1 & 8.0 & $\ldots$ \\
$700^{\circ} \mathrm{C}$ & 69.2 & 10.4 & $\cdots$ & 20.5 \\
$800^{\circ} \mathrm{C}$ & 63.4 & 10.3 & $\cdots$ & 26.3 \\
$900^{\circ} \mathrm{C}$ & 78.9 & 13.0 & $\cdots$ & 8.1 \\
\hline \hline
\end{tabular}

4(c). The Ga $3 d$ spectrum of the as-grown sample consists of $\mathrm{Ga}-\mathrm{N}$ and $\mathrm{Ga}-\mathrm{O}$ bonds. After the $\mathrm{Mn}$ implantation, the spectrum showed asymmetry at the lower bonding energy of the $\mathrm{Ga}-\mathrm{N}$ bond. The full width at half maximum (FWHM) value of the $\mathrm{Ga} 3 d$ peak was measured to be $1.65 \mathrm{eV}$ for the as-grown $p$-type $\mathrm{GaN}$, but $1.95 \mathrm{eV}$ for the $800{ }^{\circ} \mathrm{C}$ annealed $p$-type GaN. This means that an additional bonding is superimposed in the Ga $3 d$ spectra. For the Mn-implanted sample, the superimposed peak could be attributed to metallic $\mathrm{Ga}$ atoms in $\mathrm{GaN}$ due to the implantation-induced loss of nitrogen atoms. ${ }^{14}$ The difference of binding energy between $\mathrm{Ga}-\mathrm{N}$ and $\mathrm{Ga}-\mathrm{Ga}$ bonds is in good agreement with the reported value of $1.7 \mathrm{eV} .^{15}$ For the sample annealed at 700 and $800{ }^{\circ} \mathrm{C}$, a new peak could be separated at the lower bonding energy by $0.95 \mathrm{eV}$ relative to the peak of $\mathrm{Ga}-\mathrm{N}$ bonds. The $\mathrm{Ga}$ atoms in the Mn-implanted sample could make bonds with $\mathrm{N}, \mathrm{O}$, and $\mathrm{Mn}$ atoms, corresponding to $\mathrm{Ga}-\mathrm{N}, \mathrm{Ga}-\mathrm{O}$, and $\mathrm{Ga}-\mathrm{Mn}$ bonds, respectively. Considering the electron negativity of each element, the Ga-Mn bond should locate between the $\mathrm{Ga}-\mathrm{N}$ and $\mathrm{Ga}-\mathrm{Ga}$ bonds. ${ }^{15}$ Thus, the new peak should originate from the $\mathrm{Ga}-\mathrm{Mn}$ bond. After annealing at $900{ }^{\circ} \mathrm{C}$, the peak intensity for the $\mathrm{Ga}-\mathrm{Mn}$ bond decreased drastically. FWHM values and relative concentrations of deconvoluted peaks in the Ga $3 d$ spectra are summarized in Table I. Meanwhile, the N $1 s$ spectrum consists of $\mathrm{N}-\mathrm{H}$ and $\mathrm{N}-\mathrm{Ga}$ bonds, as shown in Fig. 4(d). With annealing temperature, the $\mathrm{N} 1 s$ peak intensity decreased.

The relative atomic ratio of $\mathrm{Ga} / \mathrm{N}$ was determined from integrating intensities in the Ga $3 d$ [Fig. 4(c)] and N $1 s$ spectra [Fig. 4(d)], plotted in Fig. 5. The ratio measured at a detection angle of $\theta=90^{\circ}$ in the as-implanted sample was set as 1.0 for reference. As annealing temperature increased, the $\mathrm{Ga} / \mathrm{N}$ ratio increased, indicating the production of $\mathrm{N}$ vacancies in the annealed GaN. At a smaller $\theta$, the intensity of photoelectrons emitting from the surface becomes dominant due to the inelastic mean-free path of photoelectrons. At $\theta=30^{\circ}$, the increase of the $\mathrm{Ga} / \mathrm{N}$ ratio with annealing temperature was more pronounced. This supports the fact that nitrogen atoms were preferentially diffused out to the surface during the annealing, leaving $\mathrm{N}$ vacancies near the surface region.

The change of surface band bending with annealing temperature was observed from valence band spectra, as shown in Fig. 6. The Fermi level was determined by linearly extrapolating the sloped region to the base line in the valence band spectrum of a $\mathrm{Au}$ foil, defined as the level of zero binding energy $\left(E_{F}\right)$. For the sample annealed at $900{ }^{\circ} \mathrm{C}$, the 


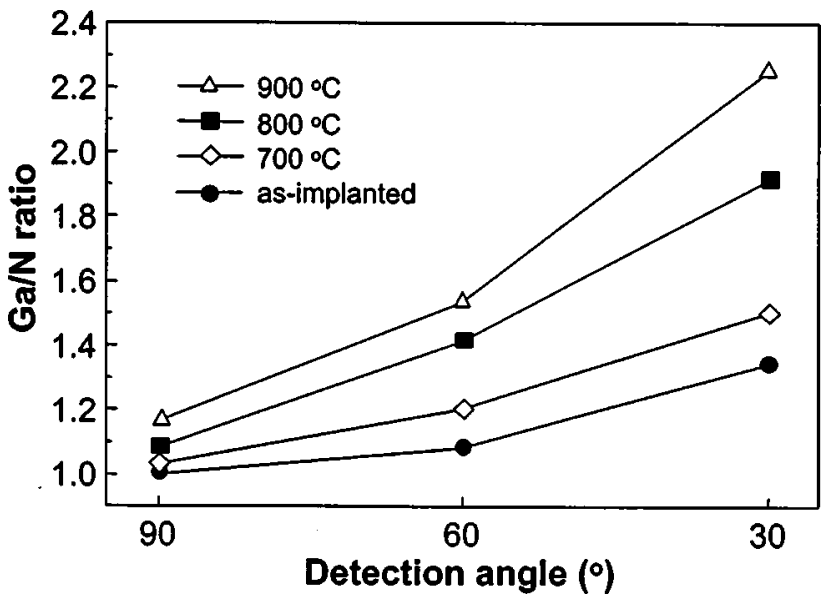

FIG. 5. Change of $\mathrm{Ga} / \mathrm{N}$ atomic ratio of $\mathrm{Mn}$-implanted $\mathrm{GaN}$ with various annealing temperatures.

Fermi level shifted by $0.5 \mathrm{eV}$ toward conduction band in comparison with the as-implanted sample. This is related to $\mathrm{N}$ vacancies produced during the annealing ${ }^{14}$ because $\mathrm{N}$ vacancies act as donors for electrons. ${ }^{16}$ However, after annealing at 700 and $800^{\circ} \mathrm{C}$, the Fermi level nearly coincides with the valence band maximum. This is due to the fact that the surface of the Mn-implanted sample changed into metallic surface, consistent with the observation of metallic $\mathrm{Ga}-\mathrm{Mn}$ bonds in Figs. 4(a) and 4(c).

\section{Optical properties}

Figure 7(a) shows PL spectra of Mn-implanted $p$-type $\mathrm{GaN}$ samples as a function of annealing temperature. For the as-grown sample, the transition related to $\mathrm{Mg}$ acceptors appeared at the energy of $2.75 \mathrm{eV}$ without yellow luminescence transition. No PL signal was observed in the as-implanted sample due to an abundance of implantation-induced imperfections. After annealing at $700^{\circ} \mathrm{C}$, a peak with a broad blue band occurred at $2.92 \mathrm{eV}$. The PL signal became more intense with annealing temperature and showed a maximum at

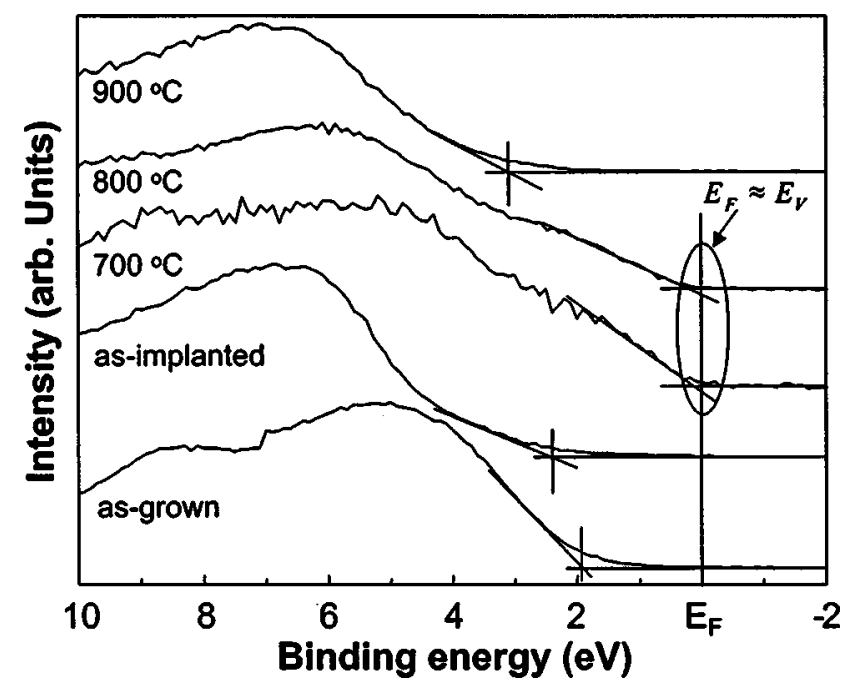

FIG. 6. Change of valence band spectra of $\mathrm{Mn}$-implanted $\mathrm{GaN}$ with various annealing temperatures.

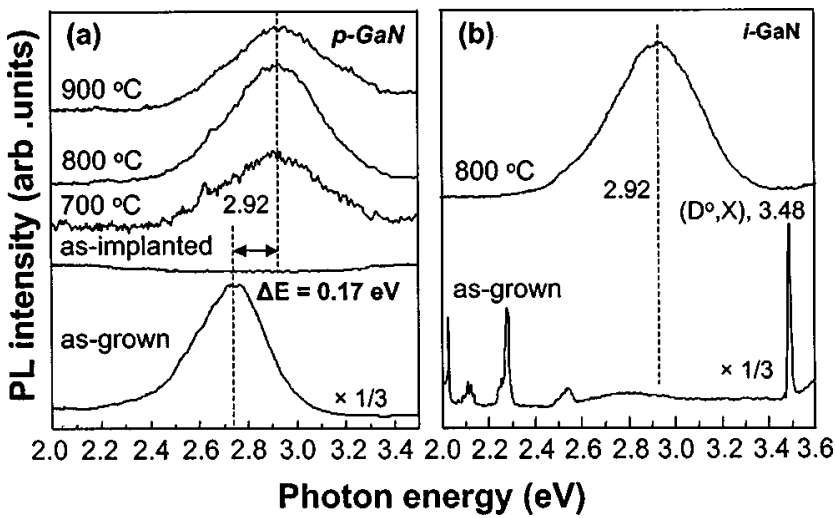

FIG. 7. (a) PL spectra at $10 \mathrm{~K}$ for as-grown, as-implanted, and annealed samples at 700,800 , and $900{ }^{\circ} \mathrm{C}$. (b) PL spectra at $10 \mathrm{~K}$ for as-grown and $800^{\circ} \mathrm{C}$ annealed undoped $\mathrm{GaN}$ samples.

$800^{\circ} \mathrm{C}$. Further increase in annealing temperature to $900{ }^{\circ} \mathrm{C}$ resulted in a decrease in the PL intensity. In order to clarify the origin of the $2.92 \mathrm{eV}$ peak, Mn ions were implanted into undoped $\mathrm{GaN}$ and subsequently annealed at $800^{\circ} \mathrm{C}$ under the same condition. The resultant PL spectra were displayed in Fig. 7(b). The $2.92 \mathrm{eV}$ emission line was also observed in undoped $\mathrm{GaN}$. This supports the fact that the transition at $2.92 \mathrm{eV}$ is not related to the $\mathrm{Mg}$ impurity in $p$-type $\mathrm{GaN}$, but apparently originates from the $\mathrm{Mn}$ impurities in $\mathrm{GaN}$.

Figure 8 shows the temperature dependence of the blue band for the Mn-implanted sample annealed at $800^{\circ} \mathrm{C}$. With increasing temperature, the blue band shifted to the lower energy $(\sim 25 \mathrm{meV}$ at $300 \mathrm{~K})$ Conduction band to acceptor $(e-A)$ transition is given by ${ }^{17}$

$$
E_{e A}=E_{g}-E_{A}+1 / 2 k_{B} T,
$$

where, $k_{B}$ is the Boltzmann constant, $E_{g}$, the band gap energy, $E_{A}$, the acceptor energy level, and $T$ is the temperature. It is clearly found that the $e-A$ transition shifts to the higher energies with increasing temperature. This indicates that the blue band of $2.92 \mathrm{eV}$ cannot be explained by $e-A$ transition. Therefore, the distinct shift of the $2.92 \mathrm{eV}$ blue band to the lower energy is a clear indication for the recombination of

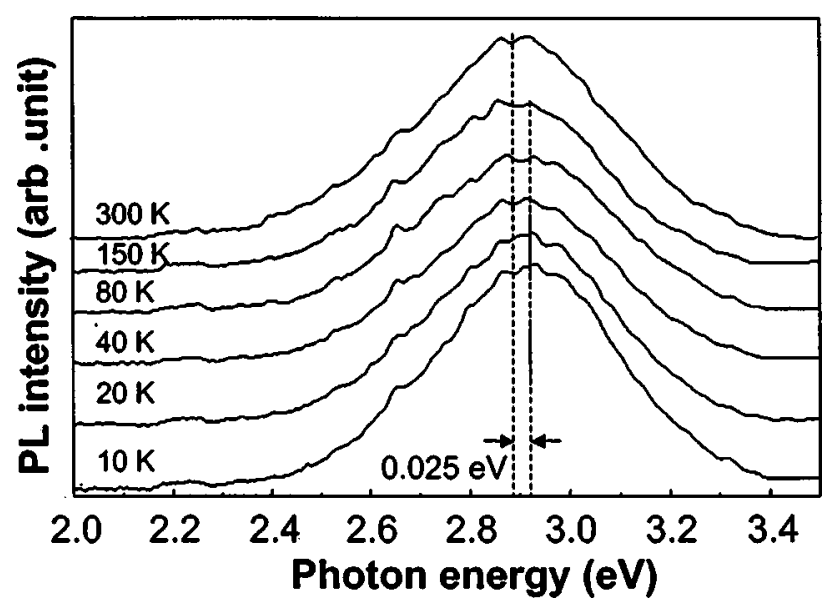

FIG. 8. Temperature dependence PL spectra of a sample annealed at $800{ }^{\circ} \mathrm{C}$. The inset shows the change of the peak energy with device temperature. 


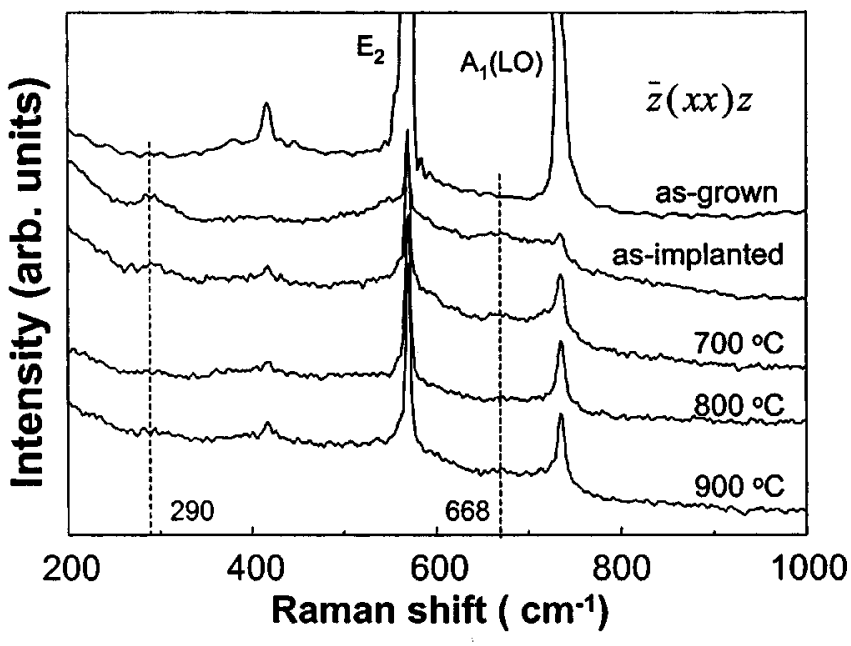

FIG. 9. Raman spectra of Mn-implanted samples as a function of annealing temperature. The measurements were carried out at room temperature.

electrons with holes trapped at spatially separated donors and acceptors, that is, the nature of donor-acceptor pair.

Figure 9 shows Raman spectra for the Mn-implanted $\mathrm{GaN}$ samples with various annealing temperatures. For the as-grown sample, two lines corresponding to the $E_{2}$ and $A_{1}$ longitudinal optical (LO) modes were observed as expected from the Raman selection rules in wurzite GaN films. ${ }^{18}$ The weak line at $418 \mathrm{~cm}^{-1}$ stems from the sapphire substrate. After the Mn implantation, the intensities of the $E_{2}$ and $A_{1}$ LO modes decreased and two additional peaks occurred at wave numbers of 290 and $670 \mathrm{~cm}^{-1}$. Whereas the intensities of the $E_{2}$ and $A_{1}$ LO modes increased with annealing temperature, the intensities of the modes at 290 and $670 \mathrm{~cm}^{-1}$ decreased. In particular, a high temperature annealing above $800{ }^{\circ} \mathrm{C}$ showed a drastic decrease in intensities of the modes. In the previous work on Raman spectroscopy for ionimplanted GaN films, the modes at 290 and $670 \mathrm{~cm}^{-1}$ appeared in samples implanted with $\mathrm{Ar}, \mathrm{Mg}, \mathrm{P}, \mathrm{C}$, and $\mathrm{Ca}$ ions. ${ }^{19}$ This means that such modes are independent of the local vibrations of Mn impurities. Therefore, it is believed that these modes at 290 and $670 \mathrm{~cm}^{-1}$ originated from the macroscopic disorder or vacancy-related defects due to the Mn implantation.

\section{DISCUSSION}

\section{A. Correlation between magnetic properties and microstructure}

In the SRPES measurements, the peak corresponding to $\mathrm{Ga}-\mathrm{Mn}$ bonds was observed in the 700 and $800^{\circ} \mathrm{C}$ annealed samples [Fig. 4(c)]. But the peak intensity for the Ga-Mn bonds significantly decreased and the ferromagnetic signal also decreased as annealing temperature increased to $900{ }^{\circ} \mathrm{C}$ [Fig. 1]. Based on the results reported previously that the ferromagnetic behavior of Mn-implanted GaN could be due to the formation of $\mathrm{Mn}_{3} \mathrm{Ga}$ phase, ${ }^{10}$ it is proposed that the $\mathrm{Ga}-\mathrm{Mn}$ bond found after annealing 700 and $800^{\circ} \mathrm{C}$ [Fig. 4(c)] contributed to the ferromagnetic property [Figs. 1 and 2].
Meanwhile, the Ga-Mn phases could not be identified in the XRD measurements [Fig. 3]. No observation of such $\mathrm{Ga}-\mathrm{Mn}$ phases might be attributed to the nano-scale size ${ }^{10}$ and random orientation of the $\mathrm{Ga}-\mathrm{Mn}$ magnetic phases. The $\mathrm{Ga}-\mathrm{Mn}$ magnetic phases reduced drastically as annealing temperature increased to $900{ }^{\circ} \mathrm{C}$. This is due to the fact that Mn preferentially interacted with $\mathrm{N}$ atoms to precipitate the Mn-N binary phases of $\mathrm{Mn}_{3} \mathrm{~N}_{2}$ and $\mathrm{Mn}_{6} \mathrm{~N}_{2.58}$, as shown in Fig. 3. Since the $\mathrm{Mn}-\mathrm{N}$ compounds are antiferromagnetic materials with Néel temperature above $300 \mathrm{~K},{ }^{20,21}$ the magnetic moment of the Mn-implanted GaN was reduced by the formation of the $\mathrm{Mn}-\mathrm{N}$ compounds.

\section{B. Correlation between magnetic properties and Mn-induced defects}

In XRD measurements, the formation of $\mathrm{Mn}_{3} \mathrm{~N}_{2}$ and $\mathrm{Mn}_{6} \mathrm{~N}_{2.58}$ phases was pronounced after the higher annealing temperature at $900^{\circ} \mathrm{C}$. This formation of $\mathrm{Mn}$ nitrides in $\mathrm{GaN}$ should change surroundings into $\mathrm{N}$-deficient condition, leading to the formation of $\mathrm{N}$ vacancies. This is supported by the result that the $\mathrm{Ga} / \mathrm{N}$ ratio at $\theta=90^{\circ}$ increased with annealing temperature [Fig. 5]. In GaN films, $\mathrm{N}$ vacancies have shallow donor levels, located at about $30-40 \mathrm{meV}$ below the conduction band edge. ${ }^{17}$ Thus, some part of the holes compensates with electrons generated from $\mathrm{N}$ vacancies, leading to the reduction of hole concentration. It was reported that the holes mediate the long-range interactions between the localized spins in the III-V magnetic semiconductors, enhancing ferromagnetic properties of the materials. ${ }^{1}$ Therefore, ferromagnetic signal reduced as the concentration of $\mathrm{N}$ vacancies increased.

The Mn-related PL band was observed at $2.92 \mathrm{eV}$ as the Mn-implanted sample was annealed [Fig. 7(a)]. Because Mn impurities in III-V compounds act as acceptors for electrons, it is suggested that the blue emission at $2.92 \mathrm{eV}$ is due to the recombination of donors such as $\mathrm{N}$ vacancies and $\mathrm{Mn}$ acceptors. It is worth noting that the peak intensity in the $800{ }^{\circ} \mathrm{C}$ annealed sample, where the strongest ferromagnetic signal was observed, was the largest among the annealed samples. In a photoexcitation process, excess carriers play an important role since the donor-to-acceptor pair recombination probability is determined by the number of donors and acceptors. $^{22}$ The increase in Mn acceptor centers would increase the probability of holes being captured to form donorto-acceptor pairs, resulting in larger PL peak intensity. From this, it is suggested that the increase in the activation of $\mathrm{Mn}$ atoms in the $800{ }^{\circ} \mathrm{C}$ annealed sample resulted in the production of radiative $\mathrm{Mn}$ centers responsible for the donor-toacceptor pair transition. Meanwhile, the intensity of the emission peak for $900^{\circ} \mathrm{C}$ annealed samples reduced [Fig. 7(a)]. This could be attributed to the minor surface decomposition during the high temperature annealing, leading to the degradation of PL signals. ${ }^{23}$

The production of lattice imperfections in Mn-implanted and annealed samples could be deduced from Raman spectra, as shown in Fig. 9. The intensities of Raman modes observed at 290 and $690 \mathrm{~cm}^{-1}$ in the Mn-implanted GaN decreased with the annealing temperature. In particular, the decrease was pronounced after annealing above $800{ }^{\circ} \mathrm{C}$. The modes 
were due to macroscopic disorders or vacancy-related defects in the ion-implanted GaN sample, not the local vibration of implanted atoms. ${ }^{19}$ Thus, it is suggested that annealing the implanted $\mathrm{GaN}$ at temperatures higher than $800^{\circ} \mathrm{C}$ resulted in the reduction of implantation-induced disorders in Mn-implanted GaN films, improving magnetic properties of the films. Consequently, it is suggested that optimum annealing temperature $\left(<900{ }^{\circ} \mathrm{C}\right)$ could be an important parameter in enhancing the ferromagnetism in the Mn-implanted and annealed $\mathrm{GaN}$ by suppressing the production of $\mathrm{N}$ vacancies

\section{CONCLUSION}

In this work, dilute magnetic semiconductor was achieved by implanting $\mathrm{Mn}$ ions into $p$-type GaN and subsequently annealing. The $\mathrm{Ga}-\mathrm{Mn}$ magnetic phases contributing to the ferromagnetic property were produced after annealing Mn-implanted $p$-type $\mathrm{GaN}$ below $800{ }^{\circ} \mathrm{C}$. Increasing the annealing temperature to $900{ }^{\circ} \mathrm{C}$ promoted the formation of antiferromagnetic $\mathrm{Mn}-\mathrm{N}$ compounds such as $\mathrm{Mn}_{6} \mathrm{~N}_{2.58}$ and $\mathrm{Mn}_{3} \mathrm{~N}_{2}$, leaving $\mathrm{N}$ vacancies. In PL measurements, the emission intensity of the Mn-related photoluminescence peak at $2.92 \mathrm{eV}$ was stronger after annealing at $800^{\circ} \mathrm{C}$, indicating the generation of higher hole concentration due to an effective Mn activation. The intensities of Raman modes at 290 and $670 \mathrm{~cm}^{-1}$ due to macroscopic disorder or defects decreased drastically after annealing above $800{ }^{\circ} \mathrm{C}$. This means that high temperature annealing $\left(>800^{\circ} \mathrm{C}\right)$ was required for high crystal quality of the Mn-implanted sample. In these results, it is suggested that ferromagnetic properties of Mnimplanted $p$-type GaN could be enhanced by optimizing annealing temperature $\left(\sim 800^{\circ} \mathrm{C}\right)$.

\section{ACKNOWLEDGMENTS}

This work was supported in part by the Korea Science and Engineering Foundation through the QuantumFunctional Semiconductor Research Center at Dongguk University in 2003, and in part by the project for "National Research Laboratory" sponsored by the Korea Institute of
Science and Technology Evaluation and Planning (KISTEP). High-resolution XRD and SRPES using synchrotron radiation were carried out at the 3C2 and 8A1 SPEM beamlines at the Pohang Accelerator Laboratory (PAL), respectively.

${ }^{1}$ H. Ohno, Science (Washington, DC, U.S.) 281, 951 (1998).

${ }^{2}$ H. Ohno, A. Shen, F. Matsukura, A. Oiwa, A. Endo, S. Katsumoto, and Y. Iye, Appl. Phys. Lett. 69, 363 (1996).

${ }^{3}$ M. L. Reed, N. A. El-Masry, H. H. Stadelmaier, M. K. Ritums, M. J. Reed, C. A. Parker, J. C. Roberts, and S. M. Bedair, Appl. Phys. Lett. 79, 3473 (2001).

${ }^{4}$ A. Oiwa, T. Slupinski, and H. Munekata, Appl. Phys. Lett. 78, 518 (2001).

${ }^{5}$ K. Takamura, F. Matsukura, D. Chiba, and H. Ohno, Appl. Phys. Lett. 81, 2590 (2002).

${ }^{6}$ F. Matsukura, E. Abe, and H. Ohno, J. Appl. Phys. 87, 6442 (2000).

${ }^{7}$ T. Diel, H. Ohno, F. Matsukura, J. Cibert, and D. Ferrand, Science (Washington, DC, U.S.) 287, 1019 (2000).

${ }^{8}$ S. Sonoda, S. Shimizu, T. Sasaki, Y. Yamamoto, and H. Hori, J. Cryst. Growth 237/239, 1358 (2002).

${ }^{9}$ Y. Shon, Y. H. Kwon, D. Y. Kim, X. Fan, D. Fu, and T. W. Kang, Jpn. J. Appl. Phys., Part 1 40, 5304 (2001).

${ }^{10}$ N. Theodoropoulou, A. F. Hebard, M. E. Overberg, C. R. Abernathy, S. J. Pearton, S. N. G. Chu, and R. G. Wilson, Appl. Phys. Lett. 78, 3475 (2001).

${ }^{11}$ R. Y. Korotkov, J. M. Gregie, and B. W. Wessels, Appl. Phys. Lett. 80, 1731 (2002).

${ }^{12}$ W. Gebicki, G. Kamler, T. Szyszko, S. Podsiadlo, and J. Strzeszewski, Appl. Phys. Lett. 76, 3870 (2000).

${ }^{13}$ B. J. Pong, C. J. Pan, Y. C. Teng, G. C. Chi, W.-H. Li, K. C. Lee, and C.-H. Lee, J. Appl. Phys. 83, 5992 (1998).

${ }^{14}$ Y. Nakano and T. Kachi, Appl. Phys. Lett. 79, 1468 (2001).

${ }^{15}$ J. F. Mouler, W. F. Strickle, P. E. Sobol, and K. D. Bomben, Handbook of $X$-Ray Photoelectron Spectroscopy (Perkin-Elmer, Eden Prairie, MN, 1992).

${ }^{16}$ P. Boguslawski, E. L. Briggs, and J. Bernholc, Phys. Rev. B 51, 17255 (1995).

${ }^{17}$ S. Fisher, C. Wetzel, E. E. Haller, and B. K. Meyer, Appl. Phys. Lett. 67, 1298 (1995).

${ }^{18}$ M. Cardona, in Light Scattering in Solids II, edited by M. Cardona and G. Güntherodt (Springer, Berlin, 1982), Vol. 50.

${ }^{19}$ W. Limmer, W. Ritter, R. Sauer, B. Mensching, C. Liu, and B. Rauschenbach, Appl. Phys. Lett. 72, 2589 (1998).

${ }^{20}$ H. Yang, H. Al-Brithen, E. Trifan, D. C. Ingram, and A. R. Smith, J. Appl. Phys. 91, 1053 (2002).

${ }^{21}$ M. N. Eddine and E. F. Bertaut, Solid State Commun. 23, 147 (1977).

${ }^{22}$ L. S. Wang, W. K. Fong, C. Surya, K. W. Cheah, W. H. Zheng, and Z. G. Wang, Solid-State Electron. 45, 1153 (2001).

${ }^{23}$ S. Nakamura, T. Mukai, M. Senoh, and N. Iwasa, Jpn. J. Appl. Phys., Part 2 31, L139 (1992). 